AperTO - Archivio Istituzionale Open Access dell'Università di Torino

\title{
Subependymal Reaction Secondary to Choroid Plexus Papilloma in a Horse
}

\section{This is the author's manuscript}

Original Citation:

Availability:

This version is available http://hdl.handle.net/2318/141593

since 2016-11-20T16:09:50Z

Published version:

DOI:10.1016/j.jevs.2013.09.003

Terms of use:

Open Access

Anyone can freely access the full text of works made available as "Open Access". Works made available under a Creative Commons license can be used according to the terms and conditions of said license. Use of all other works requires consent of the right holder (author or publisher) if not exempted from copyright protection by the applicable law. 


\title{
Subependymal Reaction Secondary to Choroid Plexus Papilloma in a Horse
}

\author{
Paulo Ricardo Dell'Armelina Rocha DVM, PhD ${ }^{\mathrm{a}}$, Andrea Bertuglia DVM ${ }^{\mathrm{a}}$, Elena Biasibetti DVM, \\ $\mathrm{PhD}^{\mathrm{a}}$, Michela Bullone DVM ${ }^{\mathrm{a}}$, Alfonso Rosamilia DVM ${ }^{\mathrm{b}}$, Loretta Masoero DVM ${ }^{\mathrm{b}}$, Maria Teresa \\ Capucchio DVM, $\mathrm{PhD}^{\mathrm{a}}$
}

${ }^{a}$ Department of Veterinary Sciences, University of Turin, Grugliasco, Italy ${ }^{\mathrm{b}}$ Istituto Zooprofilattico Sperimentale del Piemonte, Liguria e Valle d'Aosta, Turin, Italy

\begin{abstract}
Choroid plexus papilloma (CPP) is a rare, benign, intracranial neoplasm. The present report described a choroid plexus papilloma of the fourth ventricle with unusual proliferative reaction of ependymal/subependymal cells in a stallion. A single, soft neoformation, red-gray in color, with an irregular surface, resembling a cauliflower, expanding from the fourth ventricle to the cerebellar peduncles was observed. Microscopically, the neoformation was composed of a single layer of simple cuboidal to columnar epithelium with a wellvascularized papillary-arboriform pattern. Multifocal subependymal aggregates forming rosettes were observed near the mesencephalic aqueduct (MA). Glial-fibrillary-acidic-protein (GFAP) was markedly positive only in the neutrophil adjacent to the proliferative areas of the MA. Ependymal/subependymal reactions secondary to CPP have never been described in equine or human neuropathology. The capabilities of ependymal cells to regenerate and eventually proliferate are controversial and unclear and, thus, require additional investigation to understand the adaptive mechanisms of this rare pathogenic condition.
\end{abstract}

Keywords: Choroid plexus papilloma Tumour Immunohistochemistry Neuropathology

\section{Introduction}

Choroid plexus papilloma (CPP) is a brain tumor derived from the epithelium of choroid plexus [1,2]. CPP is a rare, slow-growing tumor and is histologically classified as a benign intracranial neoplasm [2] comprising less than $1 \%$ of brain tumors in humans of all ages. On the other hand, in childhood, it constitutes up to $4 \%$ of human intracranial neoplasms [2,3]. In dogs, however, choroid plexus tumors account for approximately $10 \%$ of all primary central nervous system (CNS) tumors [4]. In domestic species, CPP has been described primarily in dogs [1], but it has also been recognized sporadically in cats [5], a cow [6], a goat [7], and in horses [8-10]. There are no descriptions of CPP in horses in Italy. Moreover, ependymal proliferation with rosette formations secondary to CPP has never been described in equine or in human neuropathology. The present report describes a CPP of the fourth ventricle with an unusual proliferative reaction of ependymal cells in a 7-year-old stallion by means of gross examination, histopathology, and immunohistochemistry (IHC).

\section{Case Report}

A 7-year-old, Morgan breed stallion from the Piedmont region (Italy) was referred to the Veterinary Teaching Hospital of the University of Turin, Grugliasco, Italy, due to behavior problems. During the 6 months prior to the referral, the horse presented with periods of aggressiveness toward the owners and other domestic animals of the farm, consisting of attacks followed by bites. At that point, a neurological condition was suspected by the referring veterinarian. Subsequently, serological investigations were performed in order to exclude a local (encephalitis) or systemic infection (presumably caused by viruses). After- ward, because of the poor prognosis and at the owner's request, the horse was humanely euthanized, and a complete necropsy was performed. Differential diagnoses for main progressive CNS diseases in horses include infection by flavivirus (West Nile virus [WNV]), eastern equine encephalitis), Borna disease virus (BDV), rabies, leukoencephalomalacia, equine protozoal myeloencephalitis [11,12], Lyme disease [13], botulism [14], tetanus, and equine motor neuron disease 
[15]. Adrenocorticotropic and testosterone hormone analyses were performed from blood samples collected to evaluate the presence of a pituitary adenoma or a possible masculine aggressiveness, respectively. Moreover, serological investigations were performed. In particular, agar gel immunodiffusion test for equine infectious anemia virus (EIAV), serum neutralization for equine viral arteritis (EVA), and equine herpesvirus 1 (EHV-1) and 4 (EHV-4) infection; enzyme-linked immunoassorbed assay (ELISA), immunoglobulin G (IgG; ID Screen West Nile Competition, IDvet) and IgM (Pourquier ELISA IgM WNV; Institut Pourquier) for WNV, and finally indirect immunofluorescent antibody (IFA) test for BDV were performed from serum samples. All tests were carried out following the manufacturers' instructions with minor modifications.

The brain was fixed in $10 \%$ buffered formalin and routinely paraffin-embedded for histopathology and IHC. Slides for histopathology were routinely stained with hematoxylin-eosin (H\&E). Dewaxed and rehydrated tissue sections were processed overnight in a humidified chamber at $4-\mathrm{C}$ with indirect immunoperoxidase staining using monoclonal antibodies (mAb) Ki-67 (1:50 dilution; code M7240; Dako, Carpinteria, CA); pancytocheratin (1:200 dilution; code M3515; Dako), and glial-fibrillary-acidic-protein (GFAP; rabbit anti-cow GFAP; 1:2,000 dilu- tion; code number Z0334; Dako).

Endogenous peroxidase was blocked with $\mathrm{H}_{2} \mathrm{O}_{2}, 3 \%$, in absolute methanol for 15 minutes. Antigen retrieval was undertaken by heating sections in citrate buffer ( $\mathrm{pH} 6.0$ ) at 100-C for 15 minutes.

The antigen-antibody reaction was revealed by means of an EnVision plus horseradish peroxidase kit (code K5361; Dako), according to the manufacturer's instructions. $3,3^{0}$ - Diaminobenzidine was used as the chromogen, and all slides were counterstained with hematoxylin. Positive control tissues consisted of B-cell lymphoma for Ki-67, a mammary carcinoma for pancytocheratin, and an astrocytoma for GFAP. The brains from 2 adult horses without any neuropathological conditions from our department's archive were also stained with the above-cited IHC antibodies and staining protocols and were used as controls. Furthermore, all brain lesions were compared with age-related lesions of old horses [16] from our archives.

Assay results for adrenocorticotropic hormone and testosterone hormone were within normal limits.

Serological test results were negative for EIAV, EVA, and BDV infection. The serum neutralization assay yielded positive results for EHV-1 infection with serum titers of 1:4; for EHV-4 infection, serum titer was $>256$. ELISA results for WNV signal was positive for IgG but negative for IgM.

Gross lesions were observed only in the brain. A bilateral, pedunculated neoformation was observed in the fourth ventricle adjacent to the cerebellar peduncles. The neoformation was soft, red-gray in color, with an irregular surface resembling a cauliflower, and was expanding from the fourth ventricle to the cerebellar peduncles (Fig. $1 \mathrm{~A}$ and $1 \mathrm{~B})$. It measured approximately $2.5 \mathrm{~cm}$ in length on both sides of the cerebellar peduncles. Slight to moderate enlargement of the lateral ventricles and the mesencephalic aqueduct (MA) was also observed. Microscopically, the neoplasm was composed of cuboidal to columnar cells resembling choroid plexus cells and presented a papillary-arboriform pattern. The papillae were lined with a single layer of regular simple cells, which was supported by a well-vascularized, sometimes edematous connective tissue (Figs. 2A and 2B). Nuclei of the tumor cells were centralized, as was the nucleolus; cytoplasm was normally visible. Slight cellular pleomorphism was observed. Multi- focal neovascularization and nonsuppurative infiltration of inflammatory cells in the connective tissue were also observed.

Multifocal subependymal aggregates resembling rosettes were observed at the level of the MA. These nodules were composed of round to oval cells with abundant eosinophilic cytoplasm and centralized nuclei and nucleoli, morphologically resembling ependymal cells (Fig. 2C). Pancytocheratin (Fig. 2D) was positive only in the cytoplasm of neoplastic cells, thus confirming the epithelial origin of the neoplasia. GFAP (Fig. 2E) was markedly positive in the neutrophil adjacent to the sub-ependymal mesencephalic aggregates. Ki-67 was negative in all sections. 


\section{Discussion}

The present case was classified as World Health Organization (WHO) grade I CPP, according to the WHO guidelines for CNS tumors [2]. The IgG-positive test result for WNV indicated previous exposure to WNV, currently ceased as indicated by the IgM-negative result. No association was found between the aggressive episodes reported by the referring physician and the histopathologic lesions. The location of the CPP of the present horse is in agreement with a previous case reports in the same species [10] but different from other equine cases [9], which were located in the lateral ventricle. In humans, CPP is generally located in the lateral ventricle, whereas in dogs, CPP is most frequently observed in the fourth ventricle [4,17]. The microscopic features and IHC results from the neoplasm of the present case were in line with the literature of both veterinary and human neuropathology $[2,18]$. The negative result for Ki-67 confirmed the slow-growing behavior of the neoplasia. The sub-ependymal rosettes observed in the current case resembled those described in human neuropathology, which may be attributed to a reaction to irritating nonspecific insults such as trauma, inflammatory processes, or imbalance in cerebrospinal fluid pressure [19]. A previous study [16] reported similar but smaller subependymal nodules in adult and old horses, mostly close to the lateral References ventricles or the mesencephalic aqueduct. However, those nodules were always associated with irregularities of ependymal surface. No similar lesions were described in control animals (5 horses aged 3 months-5 years) [16]. The multifocal areas of ependymal/subependymal proliferation observed in the present case have never been reported in a horse, to the authors' knowledge. These hyperplastic areas may be related to hydrocephalus, in a mechanism by which astroglial cells and undifferentiated cell remnants of the embryonic sub- ependymal zone proliferate significantly [20]. Indeed, there is a layer of glial cells beneath the ependyma, most of which are astrocytes expressing GFAP. These cells could proliferate in response to an injury, such as ventricular dilatation, and might form subventricular nodules, sometimes including small nests or acini of ependymal cells [21]. This description is consistent with our GFAP results, indicating a marked astrogliosis in the sub-ependyma of the MA. GFAP immunopositivity around ependymal cells has also been demonstrated by electron microscopy in human medicine, where subependymal astrocytes can form stacks of their processes in the peri-ventricular zone to protect ependyma against increased cerebrospinal fluid pressure [21], which is in line with our H\&E and GFAP IHC results. Moreover, a study in veterinary medicine [22] reported a marked subependymal GFAP astrogliosis in a foal with hydranencephaly, although predominantly in areas lacking the ependymal lining. Therefore, based on the literature discussed above and in our interpretation, we suggest that the ependymal proliferations were caused by a chronic increase in the pressure on the CNS due to an increased production of liquor by the CPP or/and an obstruction of the evacuation routes. Although some controversial hypotheses have been described about regeneration and possible proliferation of ependymal cells $[19,20]$, the pathological significance and pathogenesis of these changes remain unknown and require additional investigation. Additional investigation with a larger number of clinical cases from young and adult horses may help to understand the adaptive mechanisms of this rare pathogenic condition. To the best of the authors' knowledge, this is the first description of CPP associated with a secondary adaptive hyperplasia of ependyma in a horse.

\section{Acknowledgments}

The authors declare no conflicts of interest with respect to their authorship or the publication of this article.

\section{References}

[1] Kurtz HJ, Hanlon GF. Choroid plexus papilloma in a dog. Vet Pathol 1971;8:91-5.

[2] Paulus W, Brandner S. Choroid plexus tumours. In: Louis DN, Ohgaki H, Wiestler OD, Cavenee WK, editors. WHO classification of tumours of the central nervous system. 4th ed. Lyon, France: IARC Press; 2007. p. 82-5.

[3] Mclendon RE, Bigner DD, Bigner SH, Provenzale JM. Pathology of tumors of the central nervous system. A guide to histologic diagnosis. Oxford: Oxford University Press; 2000. p. 179-82.

[4] Westworth DR, Dickinson PJ, Vernau W, Johnson EG, Bollen AW, Kass PH, et al. Choroid plexus tumors in 56 dogs (1985-2007). J Vet Intern Med 2008;22:1157-65. 
[5] Fuchs C, Meyer-Lindenberg A, Wohlsein P, Nolte I. Computer tomographic characteristics of primary brain tumors in dogs and cats. Berl Munch Tierarztl Wochenschr 2003;116:436-42.

[6] Hoenerhoff MJ, Janovitz E, Ramos-Vara J, Kiupel M. Choroid plexus papilloma in a Scottish Highland cow. J Comp Pathol 2006;135: 146-9.

[7] Klopfleisch R, Beier D, Teifke JP. Choroid plexus carcinoma in a goat. J Comp Pathol 2006;135:42-6.

[8] Haghdoost IS, Zakarian B. Neoplasms of equidae in Iran. Equine Vet J 1975;17:237-9.

[9] Pirie RS, Mayhew IG, Clarke CJ, Tremaine WH. Ultrasonographic confirmation of a space-occupying lesion in the brain of a horse: choroid plexus papilloma. Equine Vet J 1998;30:445-8.

[10] SardonD,VazquezF,CabreraP,AlonsoM.Choroidplexuspapilloma of the fourth ventricle of the plexus in a horse. J Equine Vet Science 2008;28:545-8.

[11] Snook CS, Hyman SS, Del Piero F, Palmer JE, Ostlund EN, Barr BS, et al. West Nile virus encephalomyelitis in eight horses. J Am Vet Med Assoc 2001;218:1576-9.

[12] Silva ML, Galiza GJ, Dantas AF, Oliveira RN, Iamamoto K, Achkar SM, et al. Outbreaks of Eastern equine encephalitis in northeastern Brazil. J Vet Diag Investig 2011;23:570-5.

[13] Imai DM, Barr BC, Daft B, Bertone JJ, Feng S, Hodzic E, et al. Lyme neuroborreliosis in 2 horses. Vet Pathol 2011;48:1151-7.

[14] McGorum BC, Kyles KW, Prince D, Hahn CN, Mayhew IG. Clinico-pathological features consistent with both botulism and grass sickness in a foal. Vet Rec 2003;152:334-6.

[15] Mohammed HO, Divers TJ, Summers BA, de Lahunta A. Vitamin E deficiency and risk of equine motor neuron disease. Acta Vet Scand 2007;49:17.

[16] Capucchio MT, Marquez M, Pregel P, Foradada L, Bravo M, Mattutino G, et al. Parenchymal and vascular lesions in ageing equine brains: histological and immunohistochemical studies. J Comp Pathol 2010;142:61-73.

[17] Summers BA, Cummings JF, De Lahunta A. Tumors of the central nervous system. In: Summers BA, Cummings JF, de Lahunta A, editors. Veterinary neuropathology. St. Louis, MO: Mosby; 1995. p. 373-5.

[18] Koestner A, Higgins RJ. Tumors of the nervous system. In: Meuten DJ, editor. Tumors in domestic animals. 4th ed. Ames, IA: Iowa State Press; 2002. p. 709-12.

[19] Sarnat HB. Ependymal reactions to injury. A review. J Neuropathol Exp Neurol 1995;54:1-15.

[20] Del Bigio MR. Pathophysiologic consequences of hydrocephalus. Neurosurg Clin North Am 2001;12:639-49.

[21] Graebet MB, Blakemore WF, Kreutzberg GW. Cellular pathology of the nervous system. In: Graham DI, Lantos PL, editors. Greenfield's neuropathology. 7th ed. London: Arnold Press; 2002. p. 124-91.

[22] Baiker K, Saunders N, Summers BA, Piercy RJ, Smith K. Hydra- nencephaly in a foal. Equine Vet Educ 2010;22:593-8. 
Fig. 1. (A, B) Gross view of the brain shows bilateral soft, red-gray neo- formation with an irregular surface resembling a cauliflower, measuring $2.5 \mathrm{~cm}$ on each side of the cerebellar peduncles.
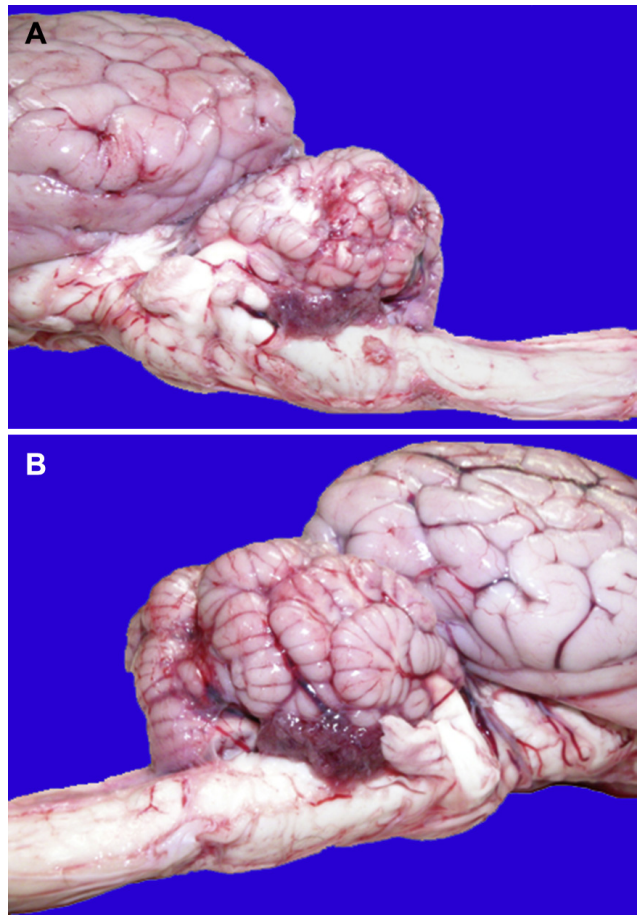

Fig. 2. (A) Brain histological section shows the papillary-arboriform pattern of the neoplasia, lined by a single layer of cuboidal to columnar epithelium supported by well-vascularized connective tissue (hematoxylin-eosin stain). (B) Subependymal aggregates composed of round to oval cells, morphologically resembling ependymal cells, are shown. (Inset) higher magnification of Fig. 1B (hematoxylin-eosin stain). (C) Pancytocheratin expression in the cytoplasm of neoplastic cells (DAB chromogen, counterstained with hematoxylin). (D) GFAP expression in the subependymal area at the level of the mesencephalic aqueduct (DAB chromogen, counterstained with hematoxylin). DAB 1/4 3,3-Diaminobenzidine; GFAP 1/4 glial-fibrillary-acidic-protein.

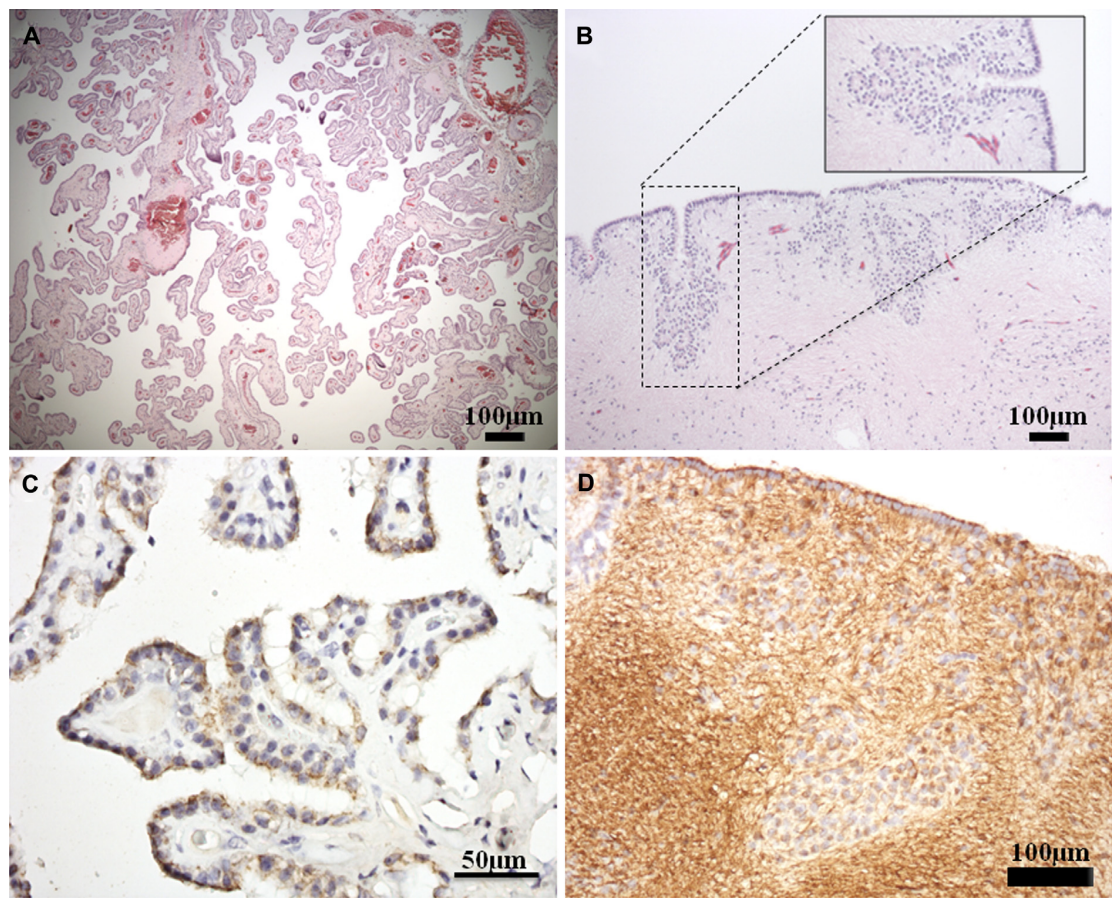

